\title{
In Quest for a Food Guide for Kuwait - An Opportunity for Innovation by Undergraduate Students Majored in Nutrition
}

\author{
Farouk El-Sabban* \\ Department of Food Science and Nutrition, College of Life Sciences, Kuwait University, State of Kuwait
}

\begin{abstract}
Received: July 05, 2016; Accepted: July 22, 2016; Published: July 27, 2016
*Corresponding author: Farouk El-Sabban, Professor of Nutrition and Physiology, Department of Food Science and Nutrition, College of Life Sciences, Kuwait University. P.O. Box 5969 - Safat 13060, Kuwait City, State of Kuwait. Telephone: +965-2463-3081; Fax: +965-2251-3929; Email: farouk.elsabban@.ku.edu.kw
\end{abstract}

Kuwait is one of the six countries that comprise the Gulf Cooperation Council (GCC) countries, most of which are oilproducing. Such countries have a total population of nearly 50 million and the population of Kuwait is currently about 3.8 million, with an approximate national to non-national ratio of nearly $1: 2$. Since the discovery of oil a few decades ago and with economic affluence, all GCC countries have gone through societal changes towards urbanization. This transition included changes in diatary habits, especially with the increasing popularity of many fast-food restaurants [1]. In spite of certain strategic risks and contaraints, basically geographic, food supply in all GCC countries is abandant [2]. With many aspects of modernday life comfort being experienced and with abandance of food supply, lifestyle has become almost sedentary. Increased food consumption and lack of sufficient level of physical activity, the global epidimic of overweight and obesity [3] has reached the populations of these countries [4]. Studies have shown that thare are alarming high rates of overweight and obesity among the population in Kauwait. Such problems are prevalent across all segments of society, from school children [5] to the elderly [6]. Such body weight gain above normal is considered as a risk factor for many chronic diseases and constitutes a serious threat to public health. Accordingly, many of the nutrition-related diseases - such as: diabetes, hypertension [7], and coronary heart disease are most prevalent in Kuwait and in this region [8]. As such adverse factors to general health are prevalent, the need for nutritional intervention is urgent. Such an effort ought to be a collective acation and involves many concerned entities. One essential means of such intervention is to enhance nutritional awareness and knowledge among different segments of society. Awareness require utilization of differenent means and tools, one of which is guiding the public to healthy nutrition and lifestyle [9].

Kuwait University is the main national institution of higher education in Kuwait. Its student body is currently about 37,000. The ratio of female to male student enrollment at Kuwait University has been nearly 2:1 since 2009 and continues to be about the same currently [10]. The University has several colleges, among which is the College of Life Sciences. Within this college is the Department of Food Science and Nutrition, which has two academic tracks that lead to granting both: a bachelor degree in food science and another bachelor degree in nutrition. The academic program in nutrition involves many basic science foundation courses and those courses that cover several aspects of public health nutrition and the nutrition of population subgroups, for juniors and seniors. In these courses, students (all are females so far) learn that many aspects of healthy nutrition and active lifestyle are essential for a healthy survival. They also learn that spreading awareness of such aspects among the lay public is a significant means towards changing towards better dieatry habits, with the resulting benefits to individuals and to the society-at-large. Students realize that devised food guides can be one istrumental factor in attracting the attention of many groups of society to practice balanced nutrition. Also, students become aware of the many food guides that have been devised all over the world, of which the "Food Guide Pyramid" of the United States Department of Agriculture is the most famous. The "Food Dome" was devised by the Arab Institute for Nutrition in Bahrain (Figure 1) a few years ago and the recently-devised "Healthy Food Palm" in Saudi Arabia (Figure 2) are those that were devised for Arab countries so far.

The author of this article taught a course on the nutrition of population subgroups to nutrition-majored students during the Spring semester of 2016. The College of Life Sciences organized the Second Kuwait International Conference on Life Sciences (KICLS) in April 2016. As the program of this conference contained a track that involved many aspects of human nutrition that involved lectures and other presentations by notable speakers and graduate students, students were invited and encouraged to attend and participate. Almost all of these nutrition-majored students attended this event and expressed their satisfaction of having such an experience and exposure. While at the conference, and under the impact of this new experience, some students raised the point of having a food guide for Kuwait to be developed. As a favorable response to this initiative, the course instructor made it known to all students that devising a food guide for Kuwait would 


\section{FOOD DOME}

DIETARY GUIDELINES FOR ARAB COUNTRIES

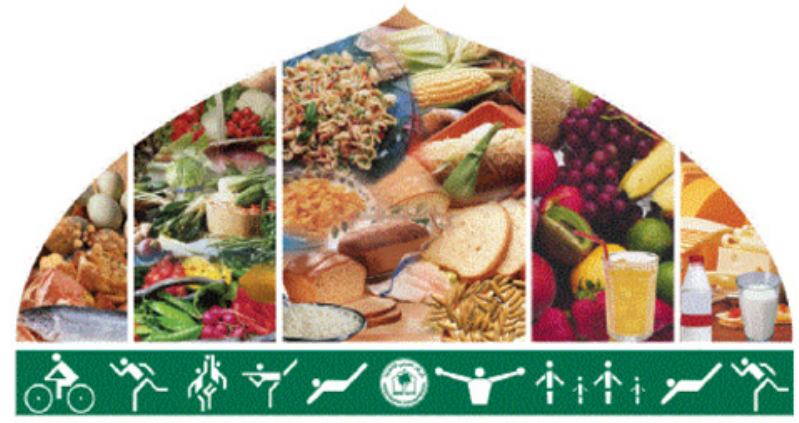

Practice medium activity like walking 30 minutes most days

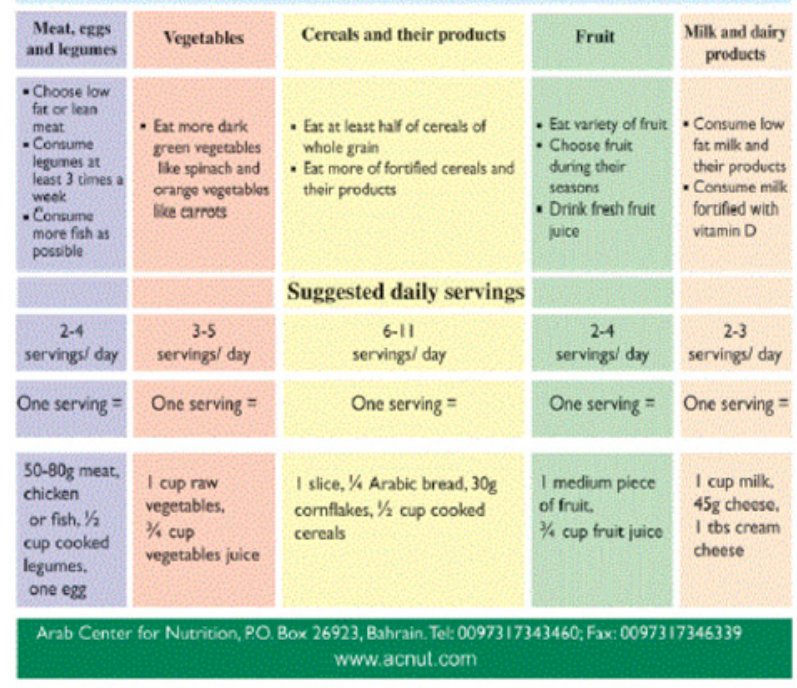

Figure 1: (Source: Google Images)

be an optional "bonus" assignment for the course. A good number of students submitted their designs, some of which are presented herein.

Students were stimulated and motivated to produce such food guides. Nearly $60 \%$ of students chose to undertake this optional assignment. Examples of student-devised food guides for Kuwait are shown in Figures 3 and 4. These designs were apparently inspired by the Kuwait Towers, one of the Land Marks for Kuwait (Figure 5). Another type of design is presented in Figure 6 - which was most likely influenced by the characteristic water towers (Figure 7) that are found in almost all localities in Kuwait. Other designs were influenced by some features, among which are the: map of Kuwait, Seal of the Sate of Kuwait, and characteristic tranditional old Kuwaiti house doors. Not all designs were available in an electronic form - some were submitted as charts and other designs were made with colored clay on wooden boards.

There are many food guides from many parts of the world available on the internet [11]. In their designs for the subject of their bonus assignment, students must have been influenced by all those available food guides. Such took into account the basic food groups and their representative items, as well as their relative proportions in the basic dietary formulation for adults. The design in Figure 6 was very unique in that it showed water as a part of this food guide. This emphasizes the significance of drinking enough water in general and, particularly, in a hotclimate country as Kuwait. In addition, all students who undertook this assignment emphasized the component of physical activity in relation to a healthy lifestyle and wellness.

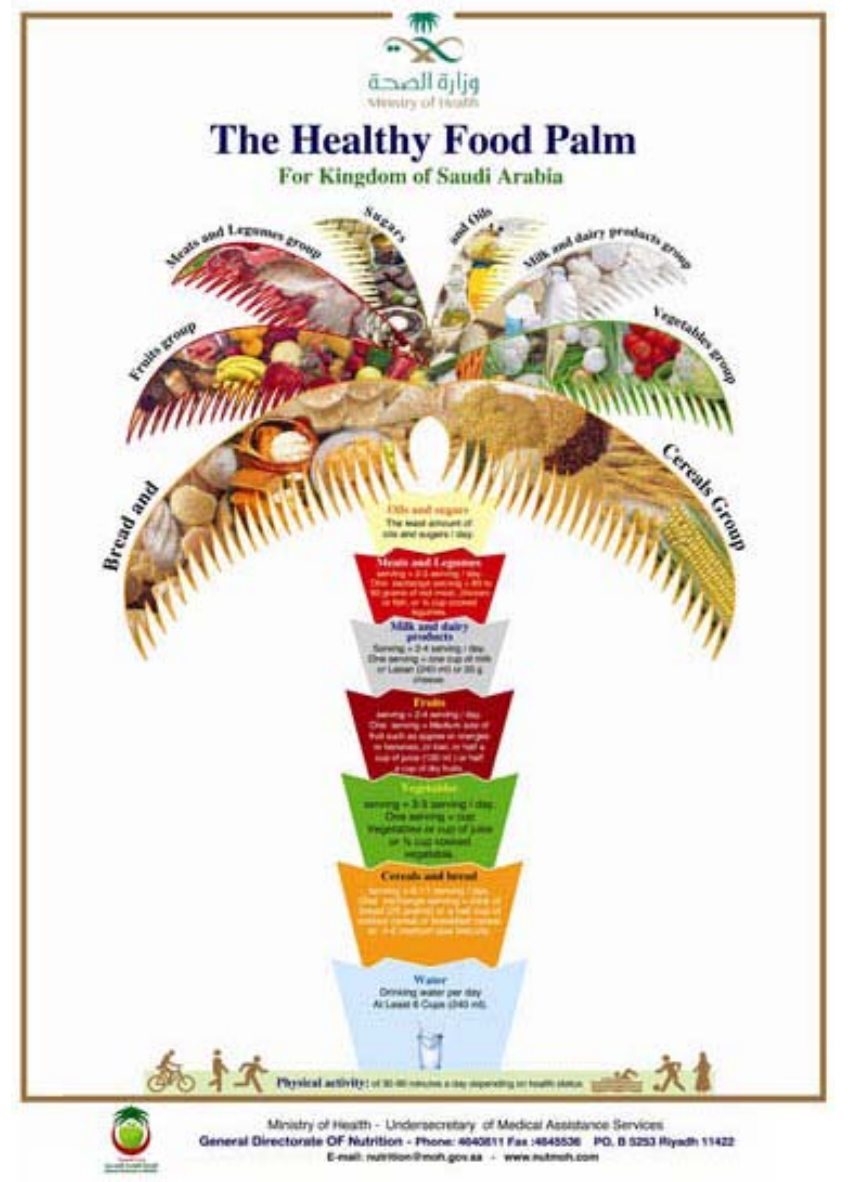

Figure 2: (Source: Google Images).

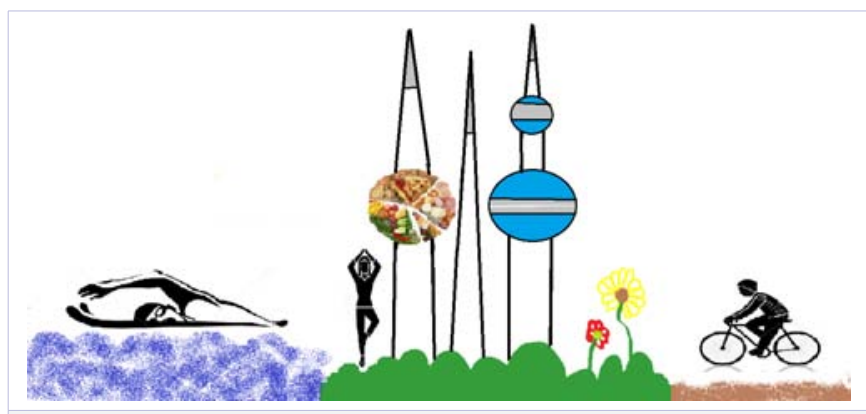

Figure 3: By a student majored in nutrition. 


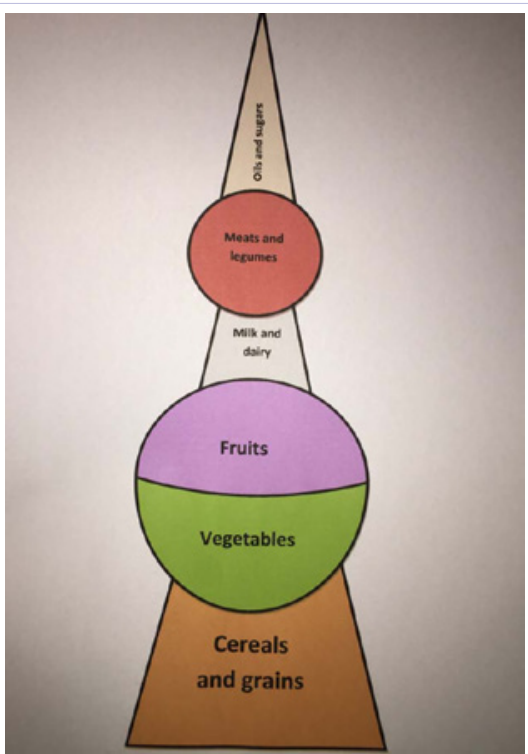

Figure 4: By a student majored in nutrition.

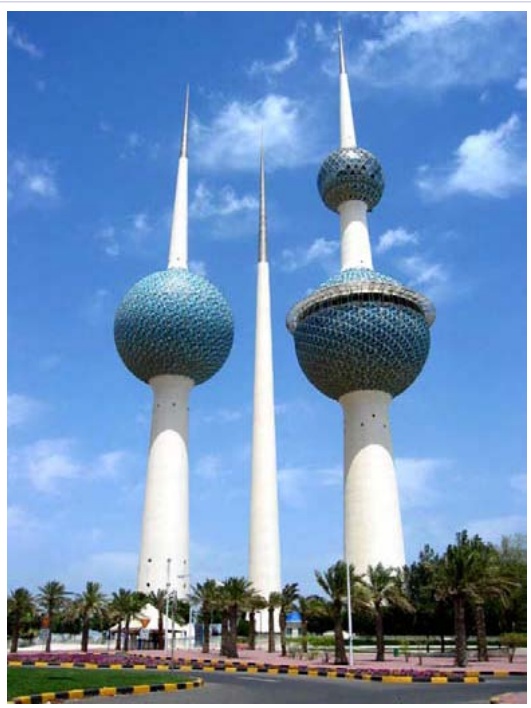

Figure 5: Kuwait Towers (source: Google Images).

Today's students in nutrition are the future nutritionists and dietitians, who will be responsible for educating and guiding the public. Their efforts will be a major influencing factor towards better dietary habits and healthy survival of the inhabitants of Kuwait.In their academic preparation within the nutrition program, students gain a wide spectrum of knowledge, that will be of benefit to them and to those who are in their immediate circle. The broad lines of basic diets for adults which state that energy from carbohydrates accounts for $45-65 \%$, approximately $15 \%$ from proteins and not more than $30 \%$ from lipids of total daily energy intake are stressed. Students also are taught that in relation to lipids, reliance should be on consuming food items that contain unsturated fatty acids. The various benefits of consuming enough servings of fruits and vegetables on a daily basis are emphasized. In addition to the knowledge that students gain in their academic preparation, they become aware that as practicing nutritionist - they will be members of professional teams that care about the general health of the public. Such health care teams must work together in harmony to privide effective services. Such emphasis is in accodance with the recently-expressed concept of the development of whole-person care models in the GCC countries [12].

While attempts to develop a food guide for Kuwait have been initiated - it is far from being officially approved. For this purpse to be achieved, there needs to be more designs that are creative and innovative and those designs would be produced

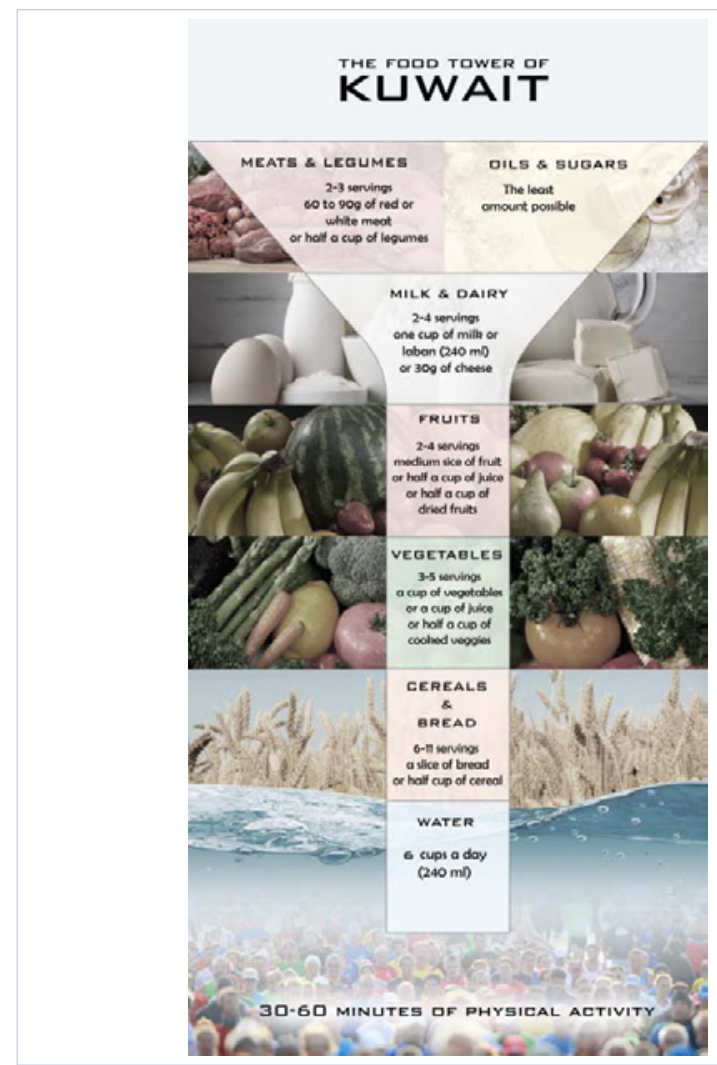

Figure 6: By a student majored in nutrition.

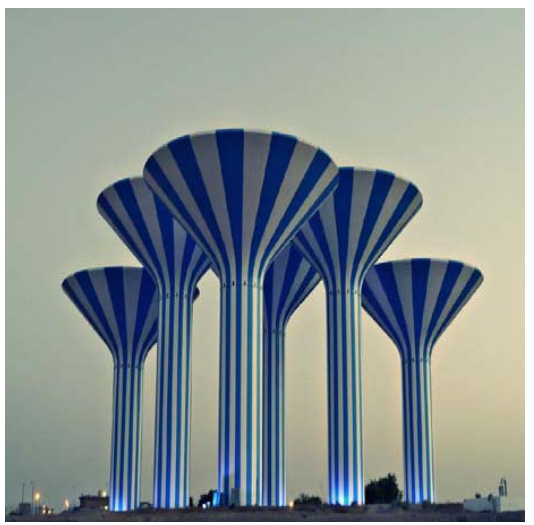

Figure 7: Water towers in Kuwait (source: Google Images). 
by professionals. Such designs ought to be in the form of colorful picturials and easy to comprehed by the lay public. Simpler forms of the food guide can cater to school children - with many picture that are in bright and attractive colors. Also, these deisgns may include contents that are more culturally-relevant and/or traditional food items and meals. Naturally, the scientific content of the produced food guides will be stcrutinized for accuracy by experts in the field. Out of the many designs produced, one will be chosen and be submitted for approval by an official authority, namely: the Administration of Food and Nutrition of the Ministry of Health in Kuwait.

In conclusion, it is commendable that undergraduate nutrition-majored students are motivated enough to take an initial step towards the development of a food guide for Kuwait. These are the future nutritionists, who will be members of health care teams that will cater for the health of the poulation in Kuwait. With their efforts towards guiding the public towards sound nutrition and healthy lifestyle, incidence of many nutritionrelated problems and diseases can be reduced.

\section{References}

1. El-Sabban F. Nutrition in Health and Disease: A Kuwaiti Societal Perspective Representing the Gulf Cooperation Council Countries. Journal of Nutrtitional Health Food Engeneering. 2015;2(5):00065 DOI: $10.15406 /$ jnhfe.2015.02.00065

2. El-Sabban F. Status of food and nutrition in the Arabian Gulf countries International Journal of Agriculture Science and Food Technology. 2015;1(1):101.
3. World Health Organization. Overweight and obesity. Fact sheet $\mathrm{N}^{\circ} 311$. Updated March 2011.

4. Musaiger AO. Overweight and Obesity in Eastern Mediterranean Region: Prevalence and Possible Causes. Journal of Obesity. 2011;2011: p.17. doi: doi.org/10.1155/2011/407237

5. Al-Isa AN. Body mass index, overweight and obesity among Kuwaiti middle school adolescents aged 10-14 years. European Journal of Clinical Nutrition. 2004;58(9):1273-1277.

6. Badr HE, Shah NM, Shah MA. Obesity among Kuwaitis aged 50 years or older: prevalence, correlates and comorbidities. The Gerontologist. 2013;53(4):555-566. doi: 10.1093/geront/gns108

7. Al-Hooti SN. Food consumption pattern for the population of the State of Kuwait based on food balanced sheets. Ecology of Food and Nutrition. 2002;41(6):501-514.

8. Musaiger AO. Diet and prevention of coronary heart disease in the Arab Middle East countries. Medical Principles and Practices. 2002;11(Suppl 2):9-16. DOI: 10.1159/000066415.

9. El-Sabban F. Nutrition awareness in Kuwait necessitates collective efforts of concerned entities. A presentation in the Second Kuwait International Conference on Life Sciences (KICLS). 2016.

10. El-Sabban F, Badr H. Assessment of nutrition knowledge and related aspects among first-year Kuwait University students. Ecology of Food and Nutrition. 2011;50(2):181-195. doi: $10.1080 / 03670244.2011 .552376$

11. Google Images. Retrieved on July 1, 2016.

12. Garduño-Diaz SD. Development of whole-person care models in the GCC. EC Nutrition ECO. 2016;1:1-2. 